\title{
Application of air compass software for source identification of semi-volatile organic compounds in Whitbourne, UK
}

\author{
S. Pongpiachan ${ }^{1}$, T. Supadit ${ }^{1}$, P. Hirunyatrakul ${ }^{2}$, \\ I. Kittikoon ${ }^{2} \& \mathrm{~S}$. Whangthamrongwit ${ }^{2}$ \\ ${ }^{I}$ NIDA Centre for Research and Development of \\ Disaster Prevention and Management, \\ School of Social and Environmental Development, \\ National Institute of Development Administration, Bangkok, Thailand \\ ${ }^{2}$ Bara Scientific Co. Ltd, Bangkok, Thailand
}

\begin{abstract}
One of the most controversial issues on air pollution field is how to quantitatively identify the emission source of gaseous species in atmospheric environment. Air Compass Software was carefully designed for this special purpose by using $\mathrm{C \#}$ program. Given that wind direction is measured as an angle $(\alpha)$ relative to true north $(0)$, mean direction was determined by using trigonometric relations to determine the direction of the resultant of individual wind vectors. The emission source strength - wind direction relationship can be represented graphically by plotting R-value of (natural logarithm of partial pressure) vs. against downwind angle ( $\alpha$ ) during the monitoring period. To apply this relationship, measured atmospheric concentrations must be expressed as partial pressures $(\mathrm{P})$, which can be converted through the use of the ideal gas law with a temperature correction. The aims of this study are to statistically quantify the relationships between emission source strengths and downwind angles of Semi-Volatile Organic Compounds (SVOCs) measured at Whitbourne monitoring stations adjacent to Worcester city, UK from 20/11/2003 to 22/12/2003 (cold-period) and from 5/5/2004 to 26/5/2004 (warm-period). Air
\end{abstract}


compass software proves that emission source strengths of each gaseous species can be significantly influenced by seasons.

Keywords: semi-volatile organic compounds, wind direction, trigonometric, air compass software, Whitbourne.

\section{Introduction}

When an air mass is flowing across a source area, it can lead to emissions and subsequently higher emissions of atmospheric concentrations of gas-phase SVOCs. It is well known that wind direction plays a significant role on atmospheric concentrations of Persistent Organic Pollutants (POPs) [1-6]. For instance, a four-fold increase in atmospheric PCBs over southern Lake Michigan when air masses were traveling from a vector between Evanston, IL, and Gary, IN has been reported by Simcik et al. [2]. A similar four-fold increase in atmospheric concentrations was observed for gas-phase phenanthrene over the northern Chesapeake Bay when winds blew from Baltimore [7]. While temperature and wind speed are obviously important parameters governing the atmospheric concentration of gas-phase SVOCs, these two parameters alone fail to entirely predict the atmospheric concentration of SVOCs. Alternatively, wind direction may also be a controlling parameter for gas-phase SVOCs concentrations. Given that wind direction is measured as an angle relative to true north $\left(0^{\circ}\right)$, mean direction was determined by using trigonometric relationships to determine the direction of the resultant of individual wind vectors [8]. To illustrate, consider a situation where maximum concentration is associated with a wind direction of $150^{\circ}$ (i.e. downwind angle $(\alpha)=150^{\circ}$ ). If we calculate the angle of wind direction relative to the angle associated with maximum concentration, we get $\operatorname{Cos}(\mathrm{WD}-\alpha)$ values of $1,0,-1$ for the wind direction of $150^{\circ}, 240^{\circ}, 330^{\circ}$ respectively. In other word, the "downwind angle $(\alpha)$ " can be referred to the angle (relative to true north) at which maximum correlation between wind direction and SVOC concentrations occur [8]. The emission source strength wind direction relationship can be represented graphically by plotting the $R$ value of $\operatorname{Ln} P$ (natural logarithm of partial pressure) vs. $\operatorname{Cos}(\mathrm{WD}-\alpha)$ against downwind angle $(\alpha)$ during the monitoring period. Additionally, it is important to note that $R$-value is the correlation coefficient between two parameters namely $\operatorname{Ln} P$ and $\operatorname{Cos}(\mathrm{WD}-\alpha)$.

\section{Methodology}

\subsection{Sampling site descriptions and monitoring period}

The field study was conducted at Whitbourne, which is located $8 \mathrm{~km}$ north west of Worcester city centre (West Midlands of the UK). There are about 542,000 people living in a 174,000 hectare area of Worcestershire, with the population density of 3.12 people $\mathrm{km}^{2}$. The sampling location was on farmland, about $2 \mathrm{~km}$ away from the nearest main road. There are no major anthropogenic emission source, like industrial emission and vehicular emission in the immediate vicinity 
of the site. However, vegetative burning, biogenic sources, soil dust, and regional source would be the major PM pollutants in this area. Intensive $\mathrm{PM}_{10}$ samples were collected during the periods from 20/11/2003 to 22/12/2003 (winter-period) and from 5/5/2004 to 26/5/2004 (summer-period). Twenty-four hour sampling was carried out every day at the sampling location.

\subsection{Sample analysis}

The extraction of SVOCs was conducted using two different sizes of Soxhlet extractors (i.e. $250 \mathrm{ml}$ for GFFs/QMFs and 1-litre for PUF plug). After $\mathrm{PM}_{10}$ determination, the GFFs/QMFs were divided in to two parts using stainless scissors. After that, the Soxhlet extraction of $\mathrm{PM}_{10}$ filter samples, $\mathrm{PM}_{10}$ filter blanks, PUF samples and PUF blanks were placed inside the Soxhlets, spiked with a known amount of internal standard (deuterated PAHs and Aliphatics), and extracted with DCM for $24 h$. The fractionation/cleanup process followed the method reported by Gogou et al. [14]. After the extraction, the DCM solvent was concentrated to dryness by a combination of rotary evaporation and blowing under a gentle nitrogen stream. The concentrated extract is then diluted in $10 \mathrm{ml}$ of $n$-hexane before application to the top of a disposable silica gel column. The extract was then fractionated into individual compound classes by flash chromatography on silica gel as follows: The concentrate was applied to the top of a $30 \times 0.7 \mathrm{~cm}$ diameter column, containing $1.5 \mathrm{~g}$ of silica gel (activated at $150^{\circ} \mathrm{C}$ for $3 \mathrm{~h}$ ). Nitrogen pressure was used to in order to obtain a flow of $1.4 \mathrm{ml}$ $\mathrm{min}^{-1}$ at the bottom of the column. The following solvents were used to elute the different compound classes: (1) $15 \mathrm{ml} n$-hexane (fraction 1, aliphatic and light molecular weight PAHs); (2) $15 \mathrm{ml}$ toluene- $n$-hexane (5.6:9.4) (fraction 2, middle and heavy molecular weight PAHs). In consideration of the toxicity of the solvent and the solubility of PAHs, toluene was selected for the study. After the fractionation, the eluates were concentrated by using rotary evaporator followed by the evaporation under a gentle nitrogen stream (set flow rate at 1.0 mbar). Because of the low dissipation capability of toluene, a percentage (5$25 \%$ ) of acetone was added to increase the volatility. The sample was further reduced to incipient prior to being made up to volume with cyclohexane (exactly $100 \mu \mathrm{l}$ in a GC/MS vial insert for both GFF/QMF and PUF samples) prior to GC/MS analysis.

All the detected compounds were identified by comparing the retention time and mass spectra of the authentic standards (i.e. 16 EPA priority pollutant PAHs, $\mathrm{MePh}$ group, alkanes $\left(\mathrm{C}_{14}-\mathrm{C}_{32}\right)$, hopanes (th, nh, hop, homo) and cholestanes (abbC, aaaC, MC, EC). Identification of the organic molecular source markers associated with atmospheric particulate matter is extremely elaborate since the markers are generally present at trace levels in a complex mixture. Application of GC/MS with low detection limits has allowed significant progress in characterisation of organic component of particulate matter. However, there are still some difficulties associated with the identification process using GC/MS.

The greatest concern is the co-elutions of unresolved isomers for some molecular markers, which result in combined mass spectra. Appropriately selected quantification ions can be beneficial to distinguish a particular mass 


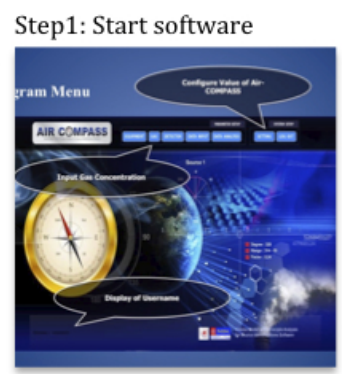

Step3: Sampling Site Configuration

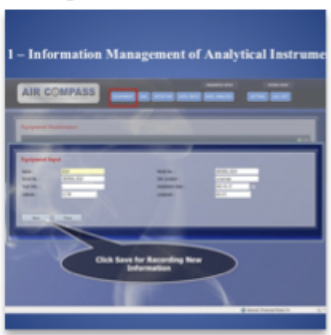

Step5: Select the Analytical Instrument Code and Collection Date
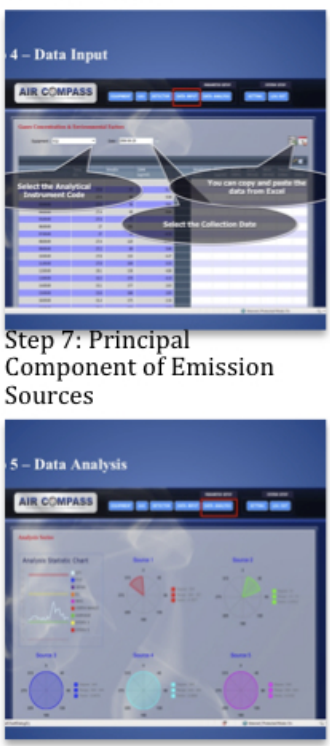

\section{Step2: Data Input}

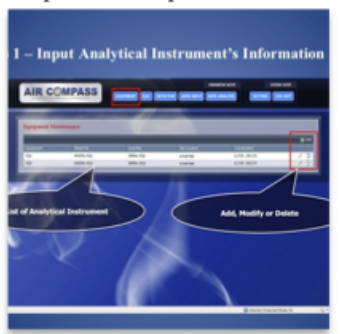

Step4: Gas Concentration Input

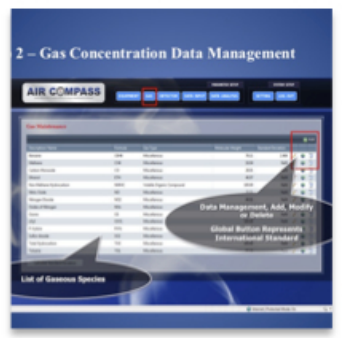

Step6: Source Identification of Gaseous Species Displayed in Google Earth

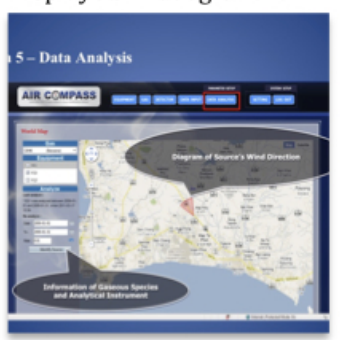

Step8: Cosine Curve of Gaseous Species

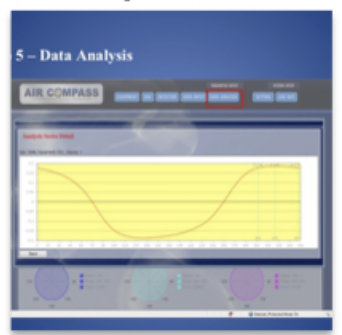

Figure 1: $\quad$ Flowchart of air compass software. 
spectrum of an individual compound from the co-eluted complex. In general, the most abundant ion serves as the quantification ion, which is the case for the PAHs, n-alkanes, hopanes and steranes in this study. The molecular markers were identified by comparing first the retention times with authentic standards within a range of $\pm 0.2 \mathrm{~min}$, secondly the quantification ions. Quantification of the compounds is based upon the Internal Standard $(I S)$ method. One of the fundamental requirements of using an $I S$ is that it displays similar physiochemical properties or the same type of substitution as the analytes because be similar to each other. A relative response factor $(R R F)$ for each native analyte was first determined. This is used for quantification, as the relative response between the internal standard $(I S)$ and the native analyte should remain constant.

\subsection{Software programming specifications}

Development Tools: Microsoft ${ }^{\circledR}$ Visual Studio 2008

Components: NET Framework 2.0, ASP NET 3.5 - Support AJAX

Telerik RadControl - Support ASP NET

Programming Language: C\#.NET + AJAX

Database: Microsoft ${ }^{\circledR}$ SQL Server or Express

Software Architectur: Tier Architecture

Other Components: Google API

\section{Results and discussion}

To apply this relationship, measured atmospheric concentrations must be expressed as partial pressures $(P)$, which can be converted through the use of the ideal gas law with a temperature correction. As illustrated in Figures 2 and 3, the $R$-values of gaseous PAHs in winter tended to be higher than those in summer. Significant positive correlations $(p<0.05)$ were found in downwind angles ranging from $50^{\circ}-120^{\circ}$ between most of the PAHs monitored in winter, suggesting the presence of common stationary sources located in north-easterly and south-easterly areas. The atmosphere, however, is a dynamic system, subject to both cyclical and non-cyclical fluctuations. There are major fluctuations in atmospheric lifetime, for instance, and this is responsible for seasonal trends. It may seem obvious that a maximum peak of cosine curve of $\mathrm{MePh}$ (Methyl Phenanthrene) group and LMW (Low Molecular Weight) alkane concentrations shifted from $70^{\circ}<\alpha<100^{\circ}$ in winter to $135^{\circ}<\alpha<165^{\circ}$ in summer. By using the atmospheric lifetime of $\mathrm{MePh}$, indicator for diesel exhausts coupled with average wind speeds in winter $\left(2.3 \pm 2.1 \mathrm{~m} \mathrm{~s}^{-1}\right)$ and summer $\left(2.2 \pm 1.1 \mathrm{~m} \mathrm{~s}^{-1}\right)$, the estimated traveling distances of $\mathrm{MePh} 1, \mathrm{MePh} 2, \mathrm{MePh} 3, \mathrm{MePh} 9$ were $407 \pm$ $79 \mathrm{~km}, 182 \pm 35 \mathrm{~km}, 177 \pm 34 \mathrm{~km}, 155 \pm 30 \mathrm{~km}$ and $71 \pm 3 \mathrm{~km}, 32 \pm 1.4 \mathrm{~km}$, $31 \pm 1.2 \mathrm{~km}, 27 \pm 1.1 \mathrm{~km}$ for winter and summer respectively. Clearly, the gaseous PAHs in winter posses longer traveling distances and thus were subject to LRAT. Since there were no significant stationary emission sources adjacent to monitoring site within radius of $60 \mathrm{M}$, the contribution of urban emission plumes becoming dominant in summer. 

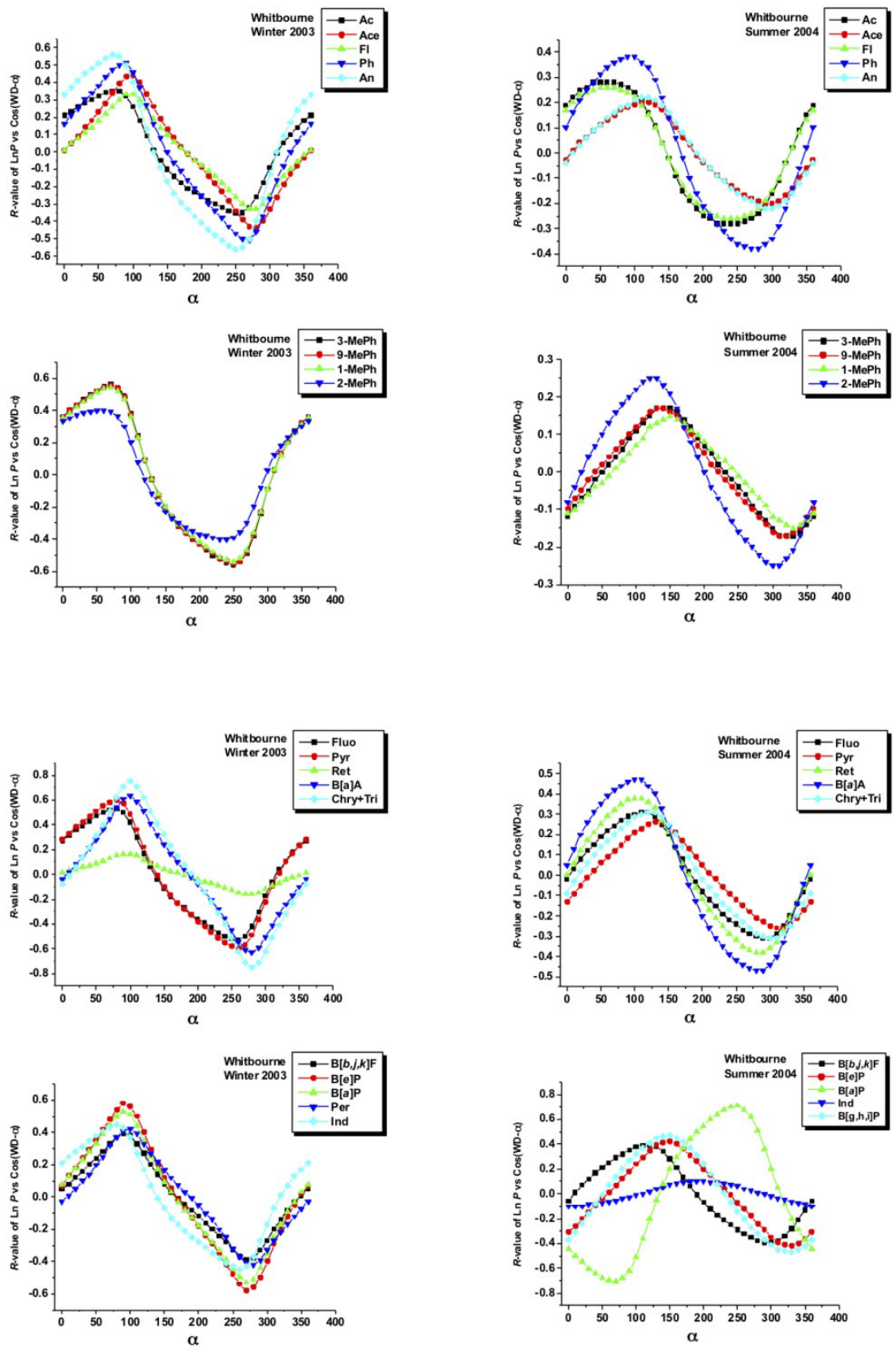

Figure 2: $\quad$ Relationship between downwind angle and $R$-value of $\operatorname{Ln} P$ vs. Cos(WD- $\alpha$ ) of SVOCs at Whitbourne. 

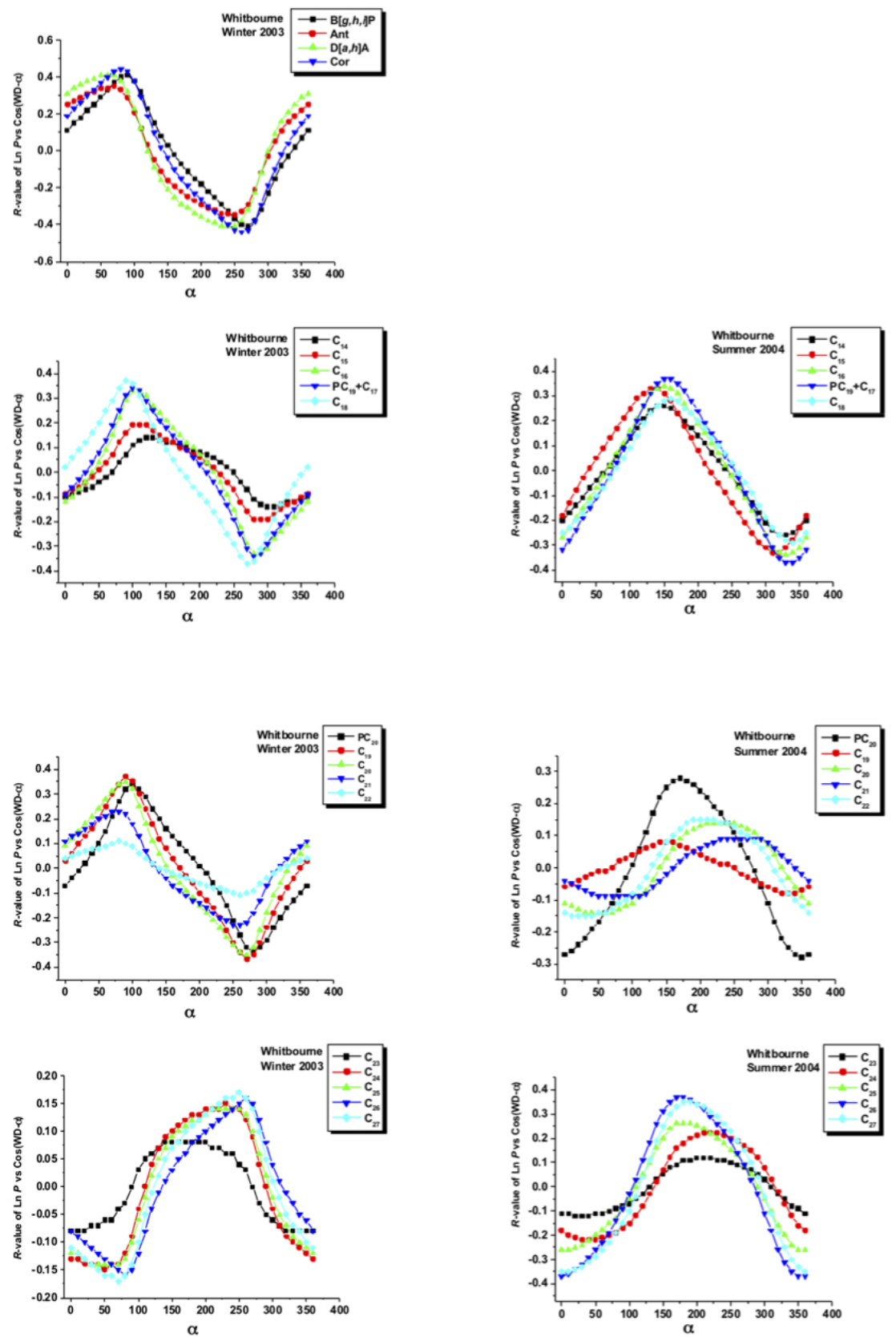

Figure 3: Relationship between downwind angle and $R$-value of $\operatorname{Ln} P$ vs. Cos(WD- $\alpha$ ) of SVOCs at Whitbourne. 
Both distribution patterns of the cosine curves and downwind angle values at the maximum peak of the corresponding curves have been found to vary seasonally and reflect the differences in physiochemical property of target compounds. For instance, the maximum peaks of cosine curves of hopanes and cholestanes detected in downwind angles ranged at $150^{\circ}<\alpha<200^{\circ}$ indicate the LRAT of petroleum biomarkers from southeastern and southern part of the UK in summer 2004. This is similar to the situation found by Abdalmogith and Harrison [9] who reported significant inter-cluster differences of air masses that was observed with the highest nitrate and sulphate contents connected with south-easterly and easterly trajectory clusters at Belfast and Harwell respectively. These two secondary inorganic aerosols are considered as chemical pollutants subject to LRAT (AQEG, 2005), and thus suggests that LRAT from southeasterly cities may also enhance the SVOCs level in Whitbourne during the warm period. Hopanes and cholestanes are environmentally stable, and thus over the long term, their transport will be affected by their tendency to continually recycle through the atmosphere. The rates of volatilisation and deposition are dependent on their chemical parameters and environmental conditions. It is also interesting to note that the $R$-values of HMW alkane (i.e. $\mathrm{C}_{28}-\mathrm{C}_{32}$ ) in summer tended to be higher than those in winter. A large fraction of these compounds derives from terrestrial and marine biological sources, such as vascular plants, animals, bacteria, macro- and microalgae [10]. Certain hydrocarbons are produced from bacterial and chemical degradation of naturally occurring lipids. Recent field experiments, however, have pointed to the presence of significant concentrations of organic matter in marine aerosol [11-12]. Colin et al. [13] found that during bloom periods, the organic fraction dominates and contributes $63 \%$ to the submicrometre aerosol mass, whereas in winter when biological activity is at its lowest, the organic fraction decreases to $15 \%$. In addition, higher concentrations of biogenic alkane gases $\mathrm{C}_{28} \mathrm{C}_{32}$ are associated with winds arriving at Whitbourne site from downwind angle ranged at $150^{\circ}-250^{\circ}$.

These findings, coupled with five-day air mass back trajectory data of May 5, $14,15,16,18,19,21,23$, corresponding to the North Atlantic plankton blooming period and thus support LRAT of these biomarkers from the Atlantic Ocean in summer. The wind direction contributing toward LRAT events in Whitbourne are best visualised through the plot of $R$-value of $\operatorname{Cos}(\mathrm{WD}-\alpha) v s$. Ln $P$ against the downwind angle $(\alpha)$. This model's ability to visually quantify the direction of LRAT of PCB has been demonstrated previously [8]. The study reported here has presented how the model has been extended to represent the LRAT of gaseous SVOCs in Whitbourne. Owing to the complicated nature of emission source strength and atmospheric chemistry of SVOCs in the gaseous phase, simulation of the exact wind direction of air mass bringing SVOCs from the source region was difficult. However, the results have provided a clear assessment of winter episodes as being due to LRAT of PAHs from northeastern cities, whereas summer episodes as being due to LRAT of PAHs and HMW alkanes from south-eastern and south-western respectively. 


\section{Conclusions}

The plot of $R$-value of $\operatorname{Cos}(\mathrm{WD}-\alpha) v s$. $\operatorname{Ln} P$ against the downwind angle $(\alpha)$ can be used to visually quantify the direction of LRAT of SVOCs. Significant positive correlations $(\mathrm{p}<0.05)$ were found in downwind angles ranging from $50^{\circ}-120^{\circ}$ between most of the PAHs monitored in winter. These results suggest the possibility of common stationary sources, plausibly the urban emission, located in north-easterly and south-easterly areas. Application of the linear regression between vehicle numbers and SVOC contents $(\mathrm{P}+\mathrm{V})$ within a radius of 60 miles and 300 miles can be used to assess the impact of LRAT to the level of SVOCs in the rural atmosphere. In general, higher $R$-values coupled with lower $p$-values are found in those samples within a radius of 300 miles, while lower $R$-values are detected in those samples within a radius of 60 miles. This supports the hypothesis that SVOCs in Whitbourne undergo LRAT.

\section{Acknowledgements}

The authors thank Bara Scientific Co., Ltd coupled with Mr. Pat and Mrs. Kristine Evans for their contribution in providing the facility to collect data and School of Social and Environmental Development, National Institute of Development Administration for financial support.

\section{References}

[1] Prevedouros, K., MacLeod, M., Jones, C. K and Sweetman, A (2004) Modelling the fate of persistent organic pollutants in Europe: parameterisation of a gridded distribution model. Environ. Pollut, Vol.128(1-2), pp. 251-261.

[2] Simcik, M. F., Zhang, H., Eisenreich, S. J and Franz, T. F. (1997) Urban Contamination of the Chicago/Coastal Lake Michigan Atmosphere by PCBs and PAHs during AEOLOS. Environmental Science \& Technology, 31, pp. 2141-2147.

[3] Brunciak, P. A., Dachs, J., Gigliotti, C. L., Nelson, E. D and Eisenreich, S. J. (2001) Atmospheric polychlorinated biphenyl concentrations and apparent degradation in coastal New Jersey. Atmospheric Environment, 35, pp. $3325-2229$.

[4] Hornbuckle, K. C., Achman, D. R and Eisenreich, S. J. (1993) Overwater and overland polychlorinated biphenyls in Green Bay, Lake Michigan. Environmental Science \& Technology, 27, pp 87-98.

[5] Offenberg, J. H and Baker, J. E. (1999) Influence of Baltimore's urban atmosphere on organic contaminants over the northern Chesapeake Bay. Journal of the Air \& Waste Management Association, 49, pp 959-965.

[6] Currado, G. M and Harrad, S. (2000) Factors influencing atmospheric concentrations of polychlorinated biphenyls in Birmingham, U.K. Environmental Science \& Technology, 34, pp 78-82. 
[7] Dachs, J., Eisenreich, S.J (2000) Adsorption onto aerosol soot carbon dominates gas-particle partitioning of polycyclic aromatic hydrocarbons. Environ. Sci. Technol. Vol.34, pp. 3690-3697.

[8] Harrad, S and Mao, H. (2004) Atmospheric PCBs and organochlorine pesticides in Birmingham, UK: concentrations, sources, temporal and seasonal trends. Atmospheric Environment, 38(10), pp. 1437-1445.

[9] Abdalmogith, S. S and Harrison, R. M (2005) The use of trajectory cluster analysis to examine the long-range transport of secondary inorganic aerosols in the UK. Atmos. Environ, Vol.39(35), pp. 6686-6695.

[10] Saliot, A (1981) Natural hydrocarbons in seawater. In Suursma, E.K and Dawson, R. eds. Marine Organic Chemistry, Amsterdam: Elsevier, pp. 327374.

[11] Kleefeld, S., Hoffer, A., Krivacsy, Z., Jennings, S. G (2002) Importance of organic and black carbon in atmospheric aerosols at Mace Head, on the West Coast of Ireland (53 degree 19'N,9degrees 54'W), Atmos. Environ, Vol.36(28), pp. 4479-4490.

[12] Putaud, J.P., Dingenen, R. V., Mangoni, M., Virkkula, A., Raes, F., Maring, H., Prospero, M. J., Sweietlicki, E., Berg, O. H., Hillamo, R. (2000) Chemical mass closure and assessment of the origin of the submicron aerosol in the marine boundary layer and the free troposphere at Tenerife during ACED-2. Tellus, Vol.52B, pp. 141-168.

[13] Colin, D. O., Maria, C. F., Fabrizia, C., Darius, C., Mihaela, M., Stefano, D., Sandro, F., Young, J. Y., Jean-Philippe, P. (2004) Biogenically driven organic contribution to marine aerosol, Nature 431, 676-680. 